\title{
On the mechanism of Rhodotorula gracilis D-amino acid oxidase: role of the active site serine 335
}

\author{
Angelo Bosellia ${ }^{\mathrm{a}}$, Luciano Piubellia ${ }^{\mathrm{a}}$, Gianluca Molla ${ }^{\mathrm{a}}$, Silvia Sacchi ${ }^{\mathrm{a}}$, Mirella S. Pilone ${ }^{\mathrm{a}}$, \\ Sandro Ghisla ${ }^{\mathrm{b}}$, Loredano Pollegioni ${ }^{\mathrm{a}, *}$ \\ ${ }^{a}$ Department of Structural and Functional Biology, University of Insubria, via J.H. Dunant 3, 21100 Varese, Italy \\ ${ }^{\mathrm{b}}$ Faculty of Biology, University of Konstanz, P.O. Box 5560-M644, D-78434 Konstanz, Germany
}

\begin{abstract}
Serine 335 at the active site of D-amino acid oxidase from the yeast Rhodotorula gracilis (RgDAAO) is not conserved in other DAAO sequences. To assess its role in catalysis, it was mutated to Gly, the residue present in mammalian DAAO, an enzyme with a 35-fold lower turnover number with D-alanine. The spectral and ligand binding properties of the S335G mutant are similar to those of wild-type enzyme, suggesting an active site with minimally altered electrostatic properties. The S335G mutant is catalytically active, excluding an essential role of S335 in catalysis. However, S335-OH contributes to the high efficiency of the mutant enzyme since the catalytic activity of the latter is lower due to a decreased rate of flavin reduction relative to wild-type RgDAAO. Catalytic rates are $\mathrm{pH}$-dependent and appear to converge to very low, but finite and similar values at low $\mathrm{pH}$ for both wild-type and S335G RgDAAO. While this dependence exhibits two apparent $\mathrm{pKs}$ with wild-type RgDAAO, with the S335G mutant a single, apparent $\mathrm{p} K \approx 8$ is observed, which is attributed to the ionization of the $\alpha \mathrm{NH}_{2}$ group of the bound substrate. Removal of S335-OH thus suppresses an apparent $\mathrm{p} K \approx 6$. Both wild-type RgDAAO and the S335G mutant exhibit a substantial deuterium solvent kinetic isotope effect $(\geq 4)$ at $\mathrm{pH}<7$ that disappears with increasing $\mathrm{pH}$ and reflects a $\mathrm{p} K_{\text {app }}=6.9 \pm 0.4$. Interestingly, the substitution suppresses the activity towards D-lactate, suggesting a role of the serine 335 in removal of the substrate $\alpha-\mathrm{OH}$ hydrogen.
\end{abstract}

Keywords: D-Amino acid oxidase; Flavoprotein; Site-directed mutagenesis; Reaction mechanism; pH effect; Proton inventory

\section{Introduction}

The flavoprotein D-amino acid oxidase (EC 1.4.3.3, DAAO) catalyzes the dehydrogenation of the D-amino acids to yield reduced enzyme, the corresponding $\alpha$-imino acids and, upon hydrolysis, $\alpha$-keto acids and ammonia

Abbreviations: RgDAAO, Rhodotorula gracilis D-amino acid oxidase; pkDAAO, pig kidney D-amino acid oxidase; $\mathrm{E} \sim \mathrm{FAD}_{\mathrm{ox}}$, oxidized enzyme; $\mathrm{E} \sim \mathrm{FAD}$ red, reduced enzyme; $\mathrm{P}$, imino acid product; KIE, kinetic isotope effect; $\mathrm{pL}(\mathrm{H}$ or $\mathrm{D})$, reading of the $\mathrm{pH}$ electrode in $\mathrm{H}_{2} \mathrm{O}$ or $\mathrm{D}_{2} \mathrm{O}$; Enzymes, D-amino acid oxidase (DAAO, EC 1.4.3.3); ophidian L-amino acid oxidase (LAAO; EC 1.4.3.2)

* Corresponding author. Tel.: +39 332 421506; fax: +39 332 421500 .

E-mail address: loredano.pollegioni@uninsubria.it (L. Pollegioni).
(Eqs. (1a) and (1b)). Subsequently reduced DAAO is reoxidized by $\mathrm{O}_{2}$ to yield $\mathrm{H}_{2} \mathrm{O}_{2}$ (Eq. (1c)):

$\mathrm{E} \sim \mathrm{FAD}_{\text {ox }}+\mathrm{D}$-aminoacid $\leftrightarrow \mathrm{E} \sim \mathrm{FAD}_{\text {red }}+$ iminoacid

iminoacid $+\mathrm{H}_{2} \mathrm{O} \rightarrow \alpha$-keto acid $+\mathrm{NH}_{3}$

$\mathrm{E} \sim \mathrm{FAD}_{\text {red }}+\mathrm{O}_{2} \rightarrow \mathrm{E} \sim \mathrm{FAD}_{\mathrm{ox}}+\mathrm{H}_{2} \mathrm{O}_{2}$

Comparison of the primary structure and the active site 3D structures of the DAAOs from Rhodotorula gracilis (RgDAAO) [1] and mammals (pkDAAO) [2,3] reveals that three residues, two tyrosines and one arginine are conserved. These residues are involved in substrate binding: the amino acid carboxylate interacts electrostatically with the $\gamma$ - and $\varepsilon$-amino groups of R285 and it 
forms $\mathrm{H}$-bonds with the $-\mathrm{OH}$ groups of the two tyrosines Y223 and Y238. In addition, the substrate $\alpha$-amino group forms two symmetric $\mathrm{H}$-bonds, in $\mathrm{RgDAAO}$ with the backbone $\mathrm{C}=\mathrm{O}$ group of $\mathrm{S} 335$ and with $\mathrm{H}_{2} \mathrm{O} 72$ (see Fig. 1A) [1]. The third substituent of the substrate $\alpha \mathrm{C}$, the side chain, is oriented toward the hydrophobic binding pocket of the active site.

The role of the active site tyrosines and arginine has been elucidated by studying the properties of corresponding mutants [4-6]. Specifically, none of these residues plays a role in the chemistry of catalysis, e.g., as $\mathrm{H}^{+}$-abstracting bases. In the free form of RgDAAO (i.e., in the absence of a ligand), R285 might have a role in the stabilization of anionic semiquinone and fully reduced flavin forms since it could rotate to within $3 \AA$ from the pyrimidine flavin moiety [5]. In addition, the Y238 side chain is assumed to act as a lid-controlling substrate/product exchange at the active site of RgDAAO [6,7].

In this paper, we report on the role of S335 in RgDAAO. This group is located in the channel connecting the active center to solvent and close to the substrate $\alpha$-amino group (Fig. 1), while in mammalian DAAO G313 and a $\mathrm{H}_{2} \mathrm{O}$ molecule are located at the equivalent position [2]. We suspected that $\mathrm{S} 335$ plays a role in bringing about the high catalytic efficiency of RgDAAO compared to the mammalian counterpart since the latter has a significantly lower turnover (Rg- and pkDAAO exhibit a $k_{\text {cat }}=345$ and $10 \mathrm{~s}^{-1}$ with D-alanine as substrate, respectively $[8,9])$. In a preceding study, we hypothesized that $\mathrm{S} 335-\mathrm{OH}$ could interact with the $\alpha \mathrm{NH}_{3}^{+}$group of the substrate $[1,10]$ and play a role in the deprotonation of the $\alpha \mathrm{NH}_{3}^{+}$group and in the transfer of the resulting $\mathrm{H}^{+}$to solvent. The aim of the present work is to verify this concept and to identify the components responsible for the comparatively high activity of RgDAAO. We have thus mutated S335 to glycine (to implement the setup found in mammalian DAAO), and have investigated the biochemical properties of the mutant in comparison to wild-type RgDAAO.
A

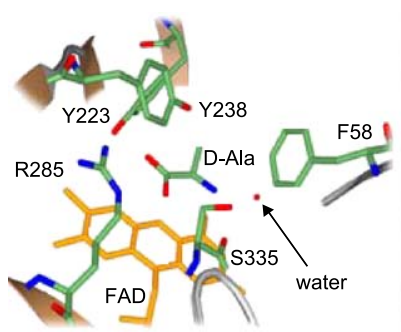

B

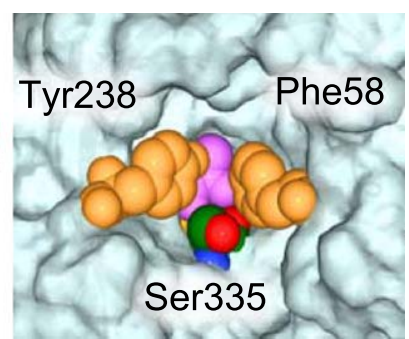

Fig. 1. (A) Active site of RgDAAO in complex with D-alanine [1]. (B) Entrance channel leading to the active site of RgDAAO. Wild-type enzyme with bound substrate D-alanine (pink) in which the $\mathrm{S} 335-\mathrm{CH}_{2}$ $\mathrm{OH}$ function (green) is positioned distal to the $\mathrm{NH}_{3}^{+}$group of D-alanine, with which it is proposed to interact during transfer of $\mathrm{H}^{+}$to solvent. Adapted from Ref. [1].

\section{Materials and methods}

\subsection{Materials}

D-Amino acids and all other compounds were purchased from Sigma. Kinetic experiments were performed in $50 \mathrm{mM}$ sodium pyrophosphate, $\mathrm{pH} 8.5,1 \%$ glycerol, $0.3 \mathrm{mM}$ EDTA, $0.5 \mathrm{mM}$ 2-mercaptoethanol and at $25{ }^{\circ} \mathrm{C}$; the other experiments in $50 \mathrm{mM}$ HEPES, $\mathrm{pH} 7.5,10 \%$ glycerol, 5 $\mathrm{mM} 2$-mercaptoethanol and $0.3 \mathrm{mM}$ EDTA at $15^{\circ} \mathrm{C}$, except where stated otherwise.

\subsection{Site-directed mutagenesis, enzyme expression, and activity assay}

Enzymatic DNA modifications were carried out according to the manufacturer's instructions and as described in Ref. [11]. The RgDAAO S335G mutant was generated by sitedirected mutagenesis using the Altered Sites ${ }^{\text {TM }}$ II Kit $[5,6]$ and the GCGTATGGCTTCTCCGGTGCGGGATACCAGC primer. The mutation eliminated a XhoI restriction site (italics); the codon for the substitution is underlined. Mutant was screened by restriction analysis. The expression vector (pT7-DAAO mutant) was obtained by sub-cloning the mutant cDNAs into the EcoRI restriction site of the pT7.7A plasmid and the presence of the desired mutations confirmed by DNA sequencing of the final plasmid. pT7-S335G plasmid was used to transform BL21(DE3)pLysS E. coli cells and the highest level of S335G mutant expression and specific activity in crude extracts $(2.5 \mathrm{U} / \mathrm{mg}$ protein $)$ was obtained by inducing cells with $1.0 \mathrm{mM}$ IPTG in the exponential growth phase $\left(\mathrm{OD}_{600} \approx 0.8\right)$ and cultivation overnight at $30{ }^{\circ} \mathrm{C}$. Fifty milligrams of pure enzyme was isolated from 101 of culture, a value close to that obtained for other RgDAAO mutants [4-6].

RgDAAO activity was assayed with an oxygen electrode at $\mathrm{pH} 8.5$ and $25^{\circ} \mathrm{C}$ with $28 \mathrm{mM}$ D-alanine as substrate and at air saturation $\left(\left[\mathrm{O}_{2}\right]=0.253 \mathrm{mM}\right)[12]$. One unit is defined as the amount of enzyme that converts $1 \mu \mathrm{mol}$ of $\mathrm{D}$-alanine per minute at $25{ }^{\circ} \mathrm{C}$.

\subsection{Spectral and ligand-binding experiments}

The extinction coefficients for the mutant RgDAAO enzyme were determined by measuring the change in absorbance upon flavin release (an $\varepsilon_{450} \mathrm{~nm}=11.3 \mathrm{mM}^{-1}$ $\mathrm{cm}^{-1}$ for free FAD was used) [4,12]. Photoreduction experiments were carried out using an anaerobic cuvette containing $\approx 8 \mu \mathrm{M}$ enzyme, $5 \mathrm{mM}$ EDTA, and $0.5 \mu \mathrm{M} 5$ deazaflavin with the cuvette immersed in a $4{ }^{\circ} \mathrm{C}$ water bath $[12,13]$. The solution was photoreduced with a $250-\mathrm{W}$ lamp and the progress of the reaction was followed spectrophotometrically. Dissociation constants for ligands were estimated spectrophotometrically by adding small volumes $(1-10 \mu \mathrm{l})$ of concentrated stock solutions to samples containing $1 \mathrm{ml}$ of $\approx 10 \mu \mathrm{M}$ enzyme, at $15^{\circ} \mathrm{C}$ [4]. 
The reaction of RgDAAO with $\mathrm{D}$ - or L-lactate was performed using an anaerobic cuvette under strict anaerobic conditions even in the presence of glucose and glucose oxidase (see below) $[1,6,8]$.

\subsection{Time-resolved, stopped-flow spectrophotometry}

Rapid kinetic measurements were performed as described previously $[6,8]$ with a BioLogic SFM-300 stopped-flow instrument equipped with a $1-\mathrm{cm}$ path length and interfaced to a J\&M diode-array detector at $25{ }^{\circ} \mathrm{C}$. Spectra were recorded from the time of mixing until completion of the reaction in the wavelength range of $250-700 \mathrm{~nm}$ and with a time constant of $1 \mathrm{~ms} / \mathrm{spectrum}$. In general, three subsequent blocks of spectra with increasing time constant were recorded. In order to minimize artifacts arising from changes in buffer composition, $\mathrm{pH}$ effect experiments were performed in a poly-buffer containing $10 \mathrm{mM} \mathrm{H}_{3} \mathrm{PO}_{4}, 10 \mathrm{mM}$ citric acid, $10 \mathrm{mM} \mathrm{H}_{3} \mathrm{BO}_{3}, 200 \mathrm{mM} \mathrm{KCl}, 1 \mathrm{mM}$ 2-mercaptoethanol, and $1 \%$ glycerol. A high $\mathrm{KCl}$ concentration was used to buffer against minor changes in ionic strength at different $\mathrm{pH}$ values. This buffer was adjusted to the appropriate $\mathrm{pH}$ by small additions of $\mathrm{HCl}$ or $\mathrm{KOH}$.

For reductive half-reaction experiments, the stoppedflow instrument, enzyme and substrate solutions were made anaerobic as detailed in [6]. As a further control of absence of oxygen from reaction mixtures, some of the experiments were also performed in the presence of $100 \mathrm{mM}$ glucose, 6 $\mathrm{nM}$ glucose oxidase, and $0.7 \mu \mathrm{M}$ catalase [8]. Reactions were performed over a wide range of substrate concentrations (at least five) in order to obtain information about both the saturation of the observed rates of flavin reduction and about $K_{\mathrm{d} \text {,app. }}$. In general, four to six experiments were conducted for each set of conditions.

Rate constants were determined in two ways. First, traces of absorbance vs. time (at 455 and $530 \mathrm{~nm}$ ) were extracted from the spectra vs. time data set. Additionally, for each set of data, the results of one experiment were analyzed using Specfit/32 software (Spectrum Software Associates, Chapel Hill, NC, USA), a program for the global analysis of data sets. The same program was used for simulations based on a three-step kinetic model (steps $k_{1} / k_{-1}, k_{2} / k_{-2}$, and $k_{5}$, see Eq. (5a) below). Secondary kinetic data were analyzed by least-means-squares curve fitting procedures and graphics were generated with KaleidaGraph software (Synergy Software, Reading, PA, USA). Rates and dissociation constants were estimated based on the equations of [14].

Enzyme-monitored turnover experiments were performed with air-equilibrated solutions at $25{ }^{\circ} \mathrm{C}$, in which oxygen was the limiting substrate. Data traces at $455 \mathrm{~nm}$ were analyzed with KaleidaGraph using published equations $[8,15]$. The concentration of D-alanine (at least five concentrations used) was varied over a sufficient range to give information about both $K_{\mathrm{m}}$ and $k_{\text {cat }}$. For all kinetic parameters, we report standard uncertainties of the theoretical fits, assuming that the uncertainties in the individual measurements are approximated by the standard uncertainty of the points from the fitted curve.

\subsection{Interpretation of $p H$ effects}

The effect of $\mathrm{pH}$ on kinetic parameters of the reductive half-reaction was analyzed as done previously for the wildtype $\mathrm{RgDAAO}$ [10]. To determine the $\mathrm{pH}$ dependence of a rate constant in which only a deprotonated form reacts, Eq. (2) was used [16]:

$k_{\mathrm{obs}}=\left(k \times K_{\mathrm{a}}\right) /\left(\left[\mathrm{H}^{+}\right]+K_{\mathrm{a}}\right)$

At high $\mathrm{pH}, k$ is constant; at low $\mathrm{pH}, k$ approaches zero directly in proportion to the decrease in concentration of the deprotonated form. In such a case, a proton is taken up or released by a group directly involved in the measured parameter. Eq. (3a) describes the $\mathrm{pH}$ dependence of a rate constant that is modified but not eliminated by the ionization [16]:

$k_{\mathrm{obs}}=\left(k_{\mathrm{AH}}\left[\mathrm{H}^{+}\right]+K_{\mathrm{a}} \times k_{\mathrm{A}-}\right) /\left(\left[\mathrm{H}^{+}\right]+K_{\mathrm{a}}\right)$

When two $\mathrm{p} K_{\mathrm{a}} \mathrm{s}$ are required to fit the data, Eq. (3b) was used [16]:

$$
\begin{aligned}
k_{\mathrm{obs}}= & \left(k_{\mathrm{AH} 1}\left[\mathrm{H}^{+}\right]+K_{\mathrm{a} 1} \times k_{\mathrm{A}-1}\right) /\left(\left[\mathrm{H}^{+}\right]+K_{\mathrm{a} 1}\right) \\
& +\left(k_{\mathrm{AH} 2}\left[\mathrm{H}^{+}\right]+K_{\mathrm{a} 2} \times k_{\mathrm{A}-2}\right) /\left(\left[\mathrm{H}^{+}\right]+K_{\mathrm{a} 2}\right)
\end{aligned}
$$

\subsection{Solvent kinetic isotope effects and proton inventories}

Buffer and substrate solutions for solvent KIE studies were prepared by dissolving the appropriate reagents in $\mathrm{D}_{2} \mathrm{O}$ as previously performed for wild-type RgDAAO [10]. The $\mathrm{pH}$ of solutions was adjusted by adding concentrated $\mathrm{DCl}$ or $\mathrm{NaOD}$ and the equation $\mathrm{pD}=$ meter reading +0.4 used to correct for the activity of $\mathrm{D}_{2} \mathrm{O}$ solutions towards the $\mathrm{pH}$ electrode [17]. Concentrated S335G RgDAAO solutions in $\mathrm{H}_{2} \mathrm{O}$ were diluted into $\mathrm{D}_{2} \mathrm{O}$ buffers such that the final proportion of $\mathrm{D}_{2} \mathrm{O}$ was $98 \%$, including correction for the protium content of the buffer components, and reductive half-reactions were performed as described above. The solvent KIE was calculated by independently determining values of $k_{\text {red }}$ (the rate constant of the first phase of flavin reduction determined at saturating D-alanine concentration; see below) from reductive half-reaction experiments in $\mathrm{H}_{2} \mathrm{O}$ and $\mathrm{D}_{2} \mathrm{O}$ at $\mathrm{pL}(\mathrm{L}=\mathrm{H}$ or $\mathrm{D}) 6,7,8$ and 9 and then calculating the ratio of $k_{\text {red }}$ values. Proton inventories at $\mathrm{pL}=6$ were done by combining buffer solutions previously adjusted to this $\mathrm{pL}$ to give the desired mixture of $\mathrm{H}_{2} \mathrm{O}$ and $\mathrm{D}_{2} \mathrm{O}$ [10]. The experimental data were fitted using Eq. (4) for two protons in movement in the transition state having fractionation factors of $0.4\left(k_{n}\right.$ is the rate constant in $n$ mole fraction $\mathrm{D}_{2} \mathrm{O}$, and $k_{0}$ is the rate constant in $\mathrm{H}_{2} \mathrm{O}$ ) [10]:

$k_{n}=k_{0}[(1-n)+n \times 0.4] \times[(1-n)+n \times 0.4]$ 


\section{Results}

\subsection{Spectral properties, ligand binding, and substrate specificity of $S 335 G \operatorname{RgDAAO}$}

S335G RgDAAO was purified as holoenzyme and shows a spectrum typical for RgDAAO. The differences among the absorption spectrum of the mutant compared to those of wild-type RgDAAO are minor and consist in a different intensity of the shoulder in the 480-500-nm region (data not shown). The $\mathrm{p} K_{\mathrm{a}}$ of deprotonation of the $\mathrm{N} 3(\mathrm{H})$ flavin position $(10.8 \pm 0.1)$ was determined by following the absorbance changes at $350 \mathrm{~nm}$ as function of $\mathrm{pH}$ and is the same within error as that of wildtype enzyme (10.6 \pm 0.2$)$. The S335G mutant is catalytically competent: anaerobic addition of a large excess of D-alanine results in immediate reduction of the flavin cofactor, and a spectrum similar to that of reduced wild-type RgDAAO is obtained. Similarly, the mutant exhibits strong kinetic stabilization of the flavin semiquinone anionic species. The extent of this effect was estimated by the method in Ref. [13] as 95\% anionic semiquinone compared to 94\% for wild-type RgDAAO [4]. Binding of sulfite correlates with the thermodynamic stability of the semiquinone form [5,18]: the $K_{\mathrm{d}}$ value for formation of the sulfite $\mathrm{N}(5)$ covalent adduct to $\mathrm{S} 335 \mathrm{G}\left(K_{\mathrm{d}}=0.23 \pm 0.04 \mathrm{mM}\right)$ is similar to that determined for wild-type RgDAAO $(0.12 \mathrm{mM})$ [4].

The binding of several ligands was assessed by following the perturbation of the visible spectrum of the FAD upon formation of the complex. Benzoate, anthranilate, and L-aspartate interact more weakly with S335G RgDAAO compared to wild-type enzyme (Table 1) [4]. An intriguing observation is the tighter interaction with L-lactate and the loss of capacity of the mutant to use D-lactate as a substrate. Thus, while wild-type RgDAAO is slowly reduced by D-lactate under anaerobic conditions as manifested by the disappearance of the absorption of the oxidized chromophore (Fig. 2), under the same experimental conditions with the $\mathrm{S} 335 \mathrm{G}$ mutant only the perturbations due to ligand binding are observed (not shown).

The S335G mutant retains the D-stereospecificity since it reacts with D-amino acids, and is not reduced by L-valine or Llactate under anaerobic conditions. For the sake of comparison, the activity of the $\mathrm{S} 335 \mathrm{G}$ mutant with the neutral D-alanine and the acidic D-aspartate amino acid was studied using the conventional assay method at fixed $(21 \%)\left[\mathrm{O}_{2}\right]$ and at $\mathrm{pH} 8.5$ [12]. The apparent maximal activity $V_{\text {max,app }}$ (as well as the kinetic efficiency $V_{\text {max,app }} / K_{\text {m,app }}$ ratio) was lower than that of wild-type RgDAAO, while the $K_{\mathrm{m} \text {,app }}$ value was unaltered (Table 1). In contrast to this, the activity of S335G DAAO with the dicarboxylic amino acid D-aspartate, expressed as apparent $V_{\max }$, is identical to that determined for wild-type DAAO. The slightly lower kinetic efficiency of the S335 mutant compared to that of wild-type RgDAAO with the acidic D-amino acid results from the higher apparent $K_{\mathrm{m}}$ value of the former.

\subsection{Steady-state studies with $S 335 G \operatorname{RgDAAO}$ and D-alanine}

A characterization of the steady-state kinetics of S335G mutant with D-alanine as substrate was carried out in some detail and at varying D-alanine and oxygen concentrations using the enzyme-monitored turnover method [15]. Fig. 3 demonstrates that, upon mixing of the enzyme with the substrate, there is a first rapid decrease in the oxidized flavin absorption that accounts for $\approx 15 \%$ of the total changes. This shows that during turnover the enzyme is present largely in the oxidized form, indicating that the overall process of reoxidation of reduced DAAO with oxygen is always faster than the reductive half-reaction. This

Table 1

Comparison of ligand binding and apparent kinetic parameters of wild-type and S335G RgDAAOs using D-alanine and D-aspartate

\begin{tabular}{|c|c|c|c|}
\hline & & Wild-type & S335G \\
\hline \multicolumn{4}{|c|}{ Binding properties, $K_{d}(m M)$ : } \\
\hline \multicolumn{2}{|l|}{ Benzoate (497 nm) } & $0.9^{\mathrm{a}}$ & $1.5 \pm 0.2$ \\
\hline \multicolumn{2}{|l|}{ Anthranilate $(540 \mathrm{~nm})$} & $1.9^{\mathrm{a}}$ & $3.6 \pm 0.9$ \\
\hline \multicolumn{2}{|l|}{ L-Aspartate $(380 \mathrm{~nm})$} & $5.6^{\mathrm{a}}$ & $9.5 \pm 1.1$ \\
\hline \multicolumn{2}{|l|}{ L-Lactate $(345 \mathrm{~nm})$} & $16.2^{\mathrm{b}}$ & $6.3 \pm 1.3$ \\
\hline \multicolumn{2}{|l|}{ D-Lactate $(480 \mathrm{~nm})$} & flavin reduction ${ }^{\mathrm{b}}$ & $10.8 \pm 1.8$ \\
\hline \multicolumn{4}{|c|}{ Steady-state kinetics (at $21 \%$ oxygen): } \\
\hline \multirow[t]{3}{*}{ D-Alanine } & $V_{\max }(\mathrm{U} / \mathrm{mg})$ & $122 \pm 4$ & $73 \pm 2$ \\
\hline & $K_{\text {m,app }}(\mathrm{mM})$ & $0.8 \pm 0.1$ & $1.1 \pm 0.1$ \\
\hline & $V_{\max } / K_{\mathrm{m}, \mathrm{app}}$ & 152 & 67 \\
\hline \multirow[t]{3}{*}{ D-Aspartate } & $V_{\max }(\mathrm{U} / \mathrm{mg})$ & $0.75 \pm 0.03$ & $0.75 \pm 0.03$ \\
\hline & $K_{\text {m,app }}(\mathrm{mM})$ & $18 \pm 2$ & $30 \pm 2$ \\
\hline & $V_{\max } / K_{\mathrm{m}, \mathrm{app}}$ & 0.042 & 0.025 \\
\hline
\end{tabular}

The wavelengths at which ligand binding was studied are indicated in parentheses. All kinetic measurements were made in $50 \mathrm{mM}$ sodium pyrophosphate, $\mathrm{pH}$ 8.5 , at air $(21 \%)$ oxygen saturation, and $25^{\circ} \mathrm{C}$.

${ }^{\text {a }}$ Ref. [4].

b Ref. [1]. 


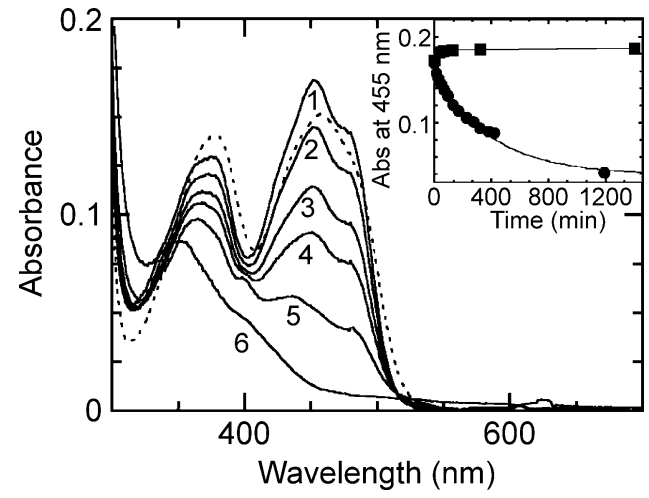

Fig. 2. Reaction of wild-type DAAO with D-lactate under anaerobic conditions. Curve (- - -) is the absorbance spectrum of $15 \mu \mathrm{M}$ wild-type DAAO (in $50 \mathrm{mM}$ HEPES, pH 7.5, 10\% glycerol, $5 \mathrm{mM}$ 2-mercaptoethanol, $0.3 \mathrm{mM}$ EDTA, and containing $100 \mathrm{mM}$ glucose and $2.7 \mathrm{nM}$ glucose oxidase) at $25{ }^{\circ} \mathrm{C}$ and under anaerobic conditions (see Materials and methods for details). Curve (1) was obtained immediately upon addition of D-lactate (final concentration 100 mM). Curves 2, 3, 4, and 5 were obtained after 50, 170, 380, and $1190 \mathrm{~min}$, respectively (all spectra have been corrected for dilution). Inset: Comparison of time courses at $455 \mathrm{~nm}$ for wild-type (O) and (ם) S335G DAAO for experiments carried out under identical conditions (see main graph). No further change in absorbance at $455 \mathrm{~nm}$ was observed for S335G mutant up to $18 \mathrm{~h}$ of incubation.

first phase is followed by a short steady-state period noticeable as a "saddle" and then by a further absorbance decrease to reach the final reduced state (Fig. 3). We refer to Refs. [8,15] for the method of analysis of the kinetic data and for a description of the corresponding equations. Briefly, Lineweaver-Burk plots of the primary data consist of a set of parallel lines (not shown) such as also found for wild-type RgDAAO [8]. This is consistent with a limiting case of a ternary complex mechanism, where some specific rate constants (i.e., $k_{-2}$, the reverse of the reduction rate, see Eq. (5)) are sufficiently small. In comparison to wild-type RgDAAO, $k_{\text {cat }}$ is reduced about fourfold, $K_{\mathrm{m}}$ for D-alanine is increased twofold, and $K_{\mathrm{m}}$ for $\mathrm{O}_{2}$ is decreased ninefold in the S335G mutant (Table 2). The good correspondence between the $\Phi_{\mathrm{O} 2}$ parameters determined for the S335G mutant and wildtype $\mathrm{RgDAAO}$ (Table 2 ) indicates that the oxygen reactivity $\left(k_{3}\right.$ in Eq. (5)) of the E $\sim \mathrm{FAD}_{\text {red }} \sim \mathrm{P}$ complex in the mutant has not changed substantially. Thus, the oxidative half-reaction of the mutant was not investigated in detail. With respect to its catalytic mechanism, the S335 mutant does not exhibit dramatic changes compared to wild-type RgDAAO.

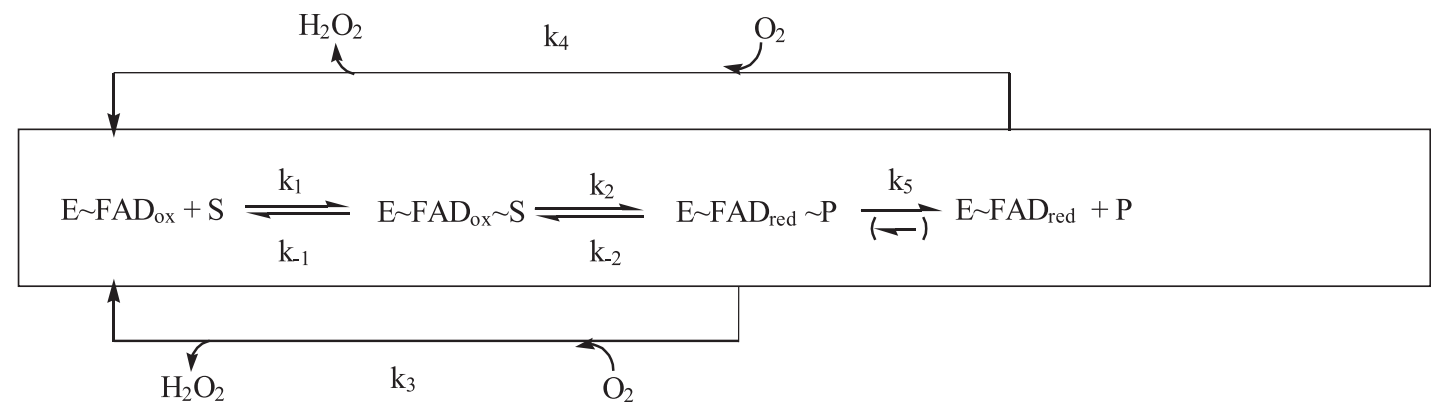

\subsection{The reductive half-reaction of $S 335 G \mathrm{RgDAAO}$ with D-alanine}

This process was studied using the stopped-flow instrument by mixing anaerobic solutions of the enzyme with varying concentrations of D-alanine, such that pseudo-first-order conditions were maintained ([alanine] $>10$-fold [enzyme]). As with wild-type RgDAAO, no spectral changes were associated with formation of the encounter complex. The course of the reaction is biphasic when followed spectrophotometrically (Fig. 4). In phase 1, the oxidized enzyme is converted to the complex

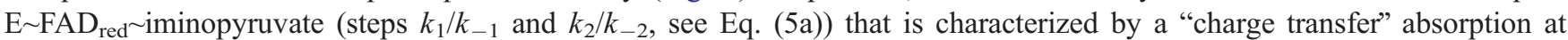
wavelength $>500 \mathrm{~nm}$. In the second phase, this intermediate decays to yield a species, the spectrum of which is consistent with the presence of free reduced enzyme (step $k_{5}$ in Eq. (5a)).

The secondary plot of the rate constants for the first phase, $k_{\mathrm{obs} 1}$, as function of $\mathrm{D}$-alanine concentration at $\mathrm{pH}$ 8.5, shows hyperbolic dependence (see Fig. 4, inset), in contrast to what was observed with wild-type RgDAAO [8]. With the latter, and under the same experimental conditions, the rate of flavin reduction is such that the reaction is over before data points can be collected (the dead time of the stopped-flow instrument is $\sim 2 \mathrm{~ms}$ ); therefore, a value at saturating substrate concentration for wild-type DAAO was never measured (it was only estimated from double- 
Table 2

Comparison of steady-state coefficients and kinetic parameters for the reductive half-reaction of wild-type and $\mathrm{S} 335 \mathrm{G}$ mutant of $\mathrm{RgDAAO}$ with $\mathrm{D}$-alanine as substrate at $\mathrm{pH} 8.5$ and $25{ }^{\circ} \mathrm{C}$

\begin{tabular}{|c|c|c|c|c|c|c|c|c|c|c|c|c|}
\hline & \multicolumn{6}{|c|}{ Steady-state kinetics } & \multicolumn{6}{|c|}{ Reductive half-reaction } \\
\hline & $\begin{array}{l}\text { Lineweaver- } \\
\text { Burk plot }\end{array}$ & $k_{\text {cat }}\left(\mathrm{s}^{-1}\right)$ & $\begin{array}{l}K_{\mathrm{m}, \mathrm{D}-\mathrm{Ala}} \\
(\mathrm{mM})\end{array}$ & $K_{\mathrm{m}, \mathrm{O}_{2}}(\mathrm{mM})$ & $\begin{array}{l}\Phi_{\text {D-Ala }} \\
{\left[(\mathrm{M} \mathrm{s}) \times 10^{-6}\right]}\end{array}$ & $\begin{array}{l}\Phi_{\mathrm{O}_{2}} \\
{\left[(\mathrm{M} \mathrm{s}) \times 10^{-6}\right]}\end{array}$ & $k_{2}\left(\mathrm{~s}^{-1}\right)$ & $K_{\mathrm{d}, \text { app }}(\mathrm{mM})$ & $\begin{array}{l}\text { Slope }\left(K_{\text {d,app }} / k_{2}\right) \\
{\left[(\mathrm{M} \mathrm{s}) \times 10^{-5}\right]}\end{array}$ & $\begin{array}{l}k_{1} \\
\left(\mathrm{mM}^{-1} \mathrm{~s}^{-1}\right)\end{array}$ & $k_{-1}\left(\mathrm{~s}^{-1}\right)$ & $k_{5}\left(\mathrm{~s}^{-1}\right)$ \\
\hline Wild-type $^{a}$ & parallel & 350 & 2.6 & 2.3 & 5.9 & 6.7 & $\begin{array}{l}510 \pm 50 \\
(500)\end{array}$ & $16 \pm 3$ & 3.0 & 30 & 500 & $2.3 \pm 0.4(2.8)$ \\
\hline S335G & parallel & $82 \pm 9.6$ & $5.1 \pm 1.2$ & $0.25 \pm 0.07$ & $160 \pm 24$ & $3.3 \pm 0.5$ & $\begin{array}{l}82 \pm 9 \\
(80)\end{array}$ & $3.8 \pm 1.1$ & 4.6 & $55 \pm 10$ & $85 \pm 30$ & $3.8 \pm 0.5(2.8)$ \\
\hline
\end{tabular}

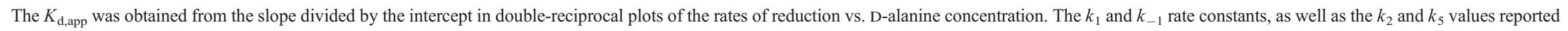
in parentheses, are the parameters determined by simulation of the experimental traces using Specfit/32 software (see text for details).

${ }^{a}$ Ref. [10]. 


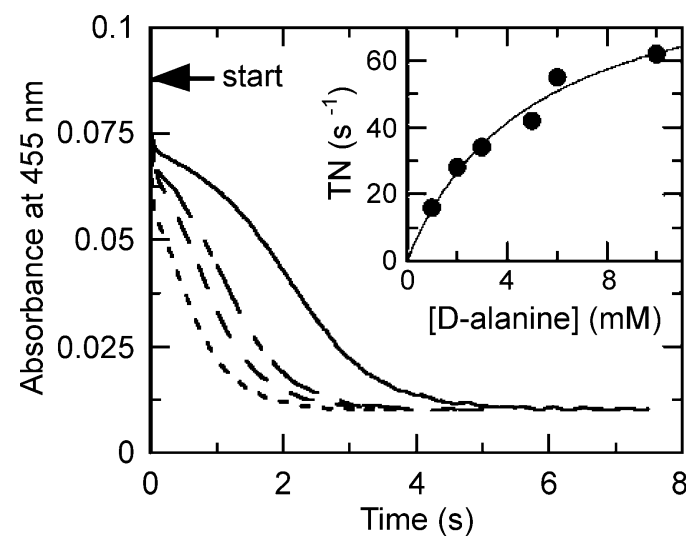

Fig. 3. Time courses of turnover of S335G RgDAAO using D-alanine. The spectral changes were followed in the stopped-flow spectrophotometer at pH 8.5 . Traces of the 455-nm changes $\left(\mathrm{Abs}_{\text {init }}=0.088\right)$ obtained upon mixing $8.7 \mu \mathrm{M}$ enzyme with the following D-alanine concentrations: $1 \mathrm{mM}(-), 2 \mathrm{mM}(---), 3$ $\mathrm{mM}(---)$, and $6 \mathrm{mM}(---)$. The traces are the average of those obtained from at least four different experiments. Inset: direct plot of the turnover data obtained from the enzyme monitored turnover traces depicted in the main graph.

reciprocal plots and then validated by traces simulation). The saturation behavior observed for the $\mathrm{S} 335 \mathrm{G}$ mutant can be described by the steps of Eq. (5a) and, in the absence of a finite $y$-axis intercept, the assumption that the reduction step is practically irreversible $\left(k_{-2} \ll k_{2}\right)$ is tenable [16,19]. The lower limits for the $k_{1}$ and $k_{-1}$ rate constants were estimated based on the setup of Eq. (5a) by simulating the experimental spectral courses with Specfit/32 (see Materials and methods for details) [10]. Parameters obtained from fitting procedures and from the simulations are listed in Table 2 and the traces obtained at different substrate concentrations are compared in Fig. 4 to the experimental data points. Simulation results show that the decrease in $k_{2}$ for the $\mathrm{S} 335 \mathrm{G}$ mutant compared to wild-type RgDAAO is accompanied by a decrease in $k_{-1}$ of similar magnitude.

The second phase in reduction corresponds to step $k_{5}$ (Eq. (5)). It is [D-alanine] independent, and its value is similar to that reported for wild-type RgDAAO (Table 2). As with wild-type enzyme, since the value of $k_{5}$ is much lower than $k_{\text {cat }}$ at $\mathrm{pH} 8.5$, it does not play a role in the catalytic cycle.

\section{4. $\mathrm{pH}$ dependence of steady-state and rapid reaction parameters of $S 335 \mathrm{Gg} D A A O$}

For the purpose of comparison, this $\mathrm{pH}$ dependence was studied as described earlier for wild-type RgDAAO [10]. The pH dependence of the rate of flavin reduction at saturating D-alanine concentration, $k_{\text {red }}$, for wild-type and S335G RgDAAOs is compared in Fig. 5A. First, over the $\mathrm{pH}$ range covered, the rates for the mutant appear to be significantly lower than those for wild-type RgDAAO. One common feature of S335G and wild-type RgDAAO is the increase in rate with pH and the attainment of plateau of activity both at low and high $\mathrm{pH}$. This is better evident with the mutant even if values at $\mathrm{pH}<6 \mathrm{could}$

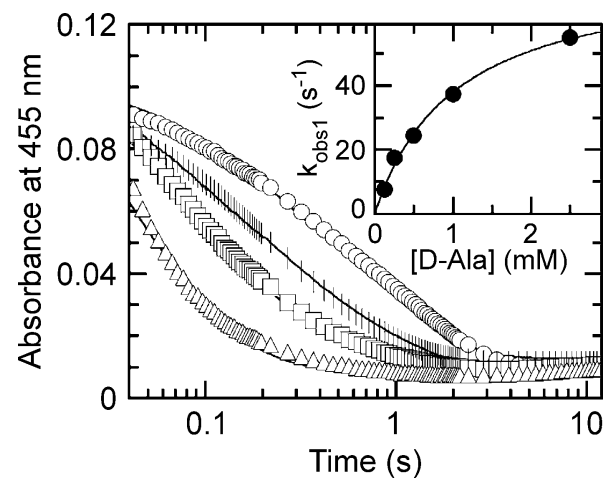

Fig. 4. Time courses of the anaerobic reduction of S335G RgDAAO by D-alanine followed at 455 nm. Anaerobic solutions of $10 \mu \mathrm{M}$ S335G RgDAAO with $0.25 \mathrm{mM}(\mathrm{O}), 0.5 \mathrm{mM}(\mid), 1 \mathrm{mM}(\square)$, and $2.5 \mathrm{mM}(\triangle)$ D-alanine were mixed in the stopped-flow instrument, at pH 8.5 and $25{ }^{\circ} \mathrm{C}$. The solid lines were obtained by simulating the sequence of steps shown in Eq. (5a) and the known extinction coefficients for the oxidized and reduced enzyme forms using the Specfit/32 software. Inset: Dependence of the observed first rate of anaerobic reduction $\left(k_{\mathrm{obs} 1}\right)$ for S335G RgDAAO on [D-alanine]. The data points were obtained by analyzing the traces in the main graph (error bars are smaller than the symbols used). 
not be collected due to instability of the protein. One major difference between the mutant and wild-type enzyme is that the data for the former can be fit satisfactorily using Eq. (3a) (finite value for $k_{2}$ at $\mathrm{pH}<\mathrm{p} K_{\mathrm{a}}$ and one ionization) while for the latter a two-ionization equation (Eq. (3b)) is required [10].
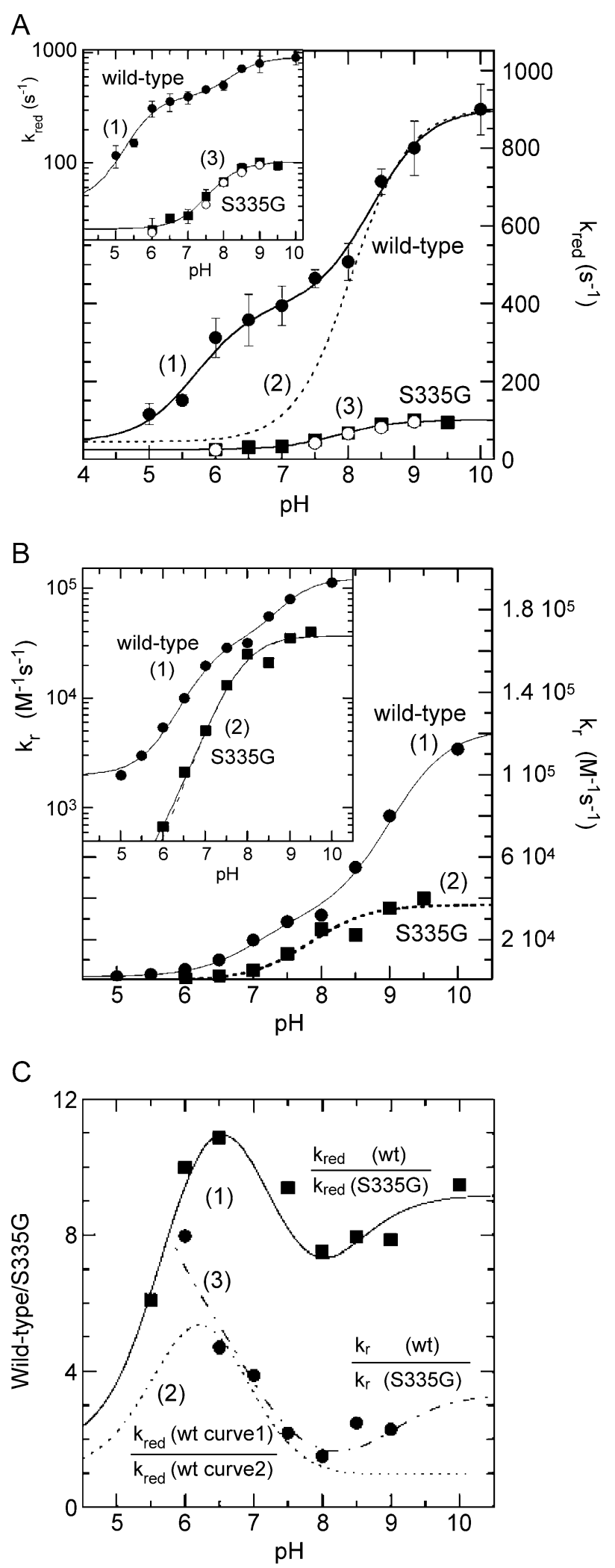
Table 3

Kinetic parameters for the reductive half-reaction of S335G RgDAAO with $\mathrm{D}$-alanine at various $\mathrm{pL}$ values $(\mathrm{L}=\mathrm{H}$ or $\mathrm{D})$

\begin{tabular}{|c|c|c|c|c|c|c|c|c|}
\hline $\mathrm{pL}$ & & $\begin{array}{l}k_{1} \\
\left(\mathrm{M}^{-1} \mathrm{~s}^{-1}\right)\end{array}$ & $k_{-1}\left(\mathrm{~s}^{-1}\right)$ & $k_{2}\left(\mathrm{~s}^{-1}\right)$ & $k_{-2}\left(\mathrm{~s}^{-1}\right)$ & $k_{5}\left(\mathrm{~s}^{-1}\right)$ & $\begin{array}{l}K_{\mathrm{d}, \text { theor }} \\
(\mathrm{mM})\end{array}$ & $\begin{array}{l}K_{\mathrm{d}, \mathrm{obs}} \\
(\mathrm{mM})\end{array}$ \\
\hline \multirow[t]{2}{*}{6.0} & $\mathrm{H}_{2} \mathrm{O}$ & $1.8 \times 10^{5}$ & $1.3 \times 10^{4}$ & 25 & 3.2 & 1.6 & 72 & 37 \\
\hline & $\mathrm{D}_{2} \mathrm{O}$ & $1.8 \times 10^{5}$ & $1.3 \times 10^{4}$ & 6 & 3.2 & 1.6 & 72 & 37 \\
\hline 6.5 & $\mathrm{H}_{2} \mathrm{O}$ & & & 31 & & 2.8 & & 15 \\
\hline \multirow[t]{2}{*}{7.0} & $\mathrm{H}_{2} \mathrm{O}$ & $2 \times 10^{5}$ & 1050 & 30 & 3 & 1.7 & 5 & 13 \\
\hline & $\mathrm{D}_{2} \mathrm{O}$ & $2 \times 10^{5}$ & 1050 & 18 & 3 & 2 & 5 & 8 \\
\hline 7.5 & $\mathrm{H}_{2} \mathrm{O}$ & & & 50 & & 2 & & 3.8 \\
\hline \multirow[t]{2}{*}{8.0} & $\mathrm{H}_{2} \mathrm{O}$ & $1.5 \times 10^{5}$ & 60 & 68 & b.d. & 3 & 1.0 & 1.5 \\
\hline & $\mathrm{D}_{2} \mathrm{O}$ & $1.0 \times 10^{5}$ & 60 & 55 & b.d. & 2.8 & 1.2 & 3.8 \\
\hline 8.5 & $\mathrm{H}_{2} \mathrm{O}$ & $5.5 \times 10^{4}$ & 85 & 90 & & 3.8 & 1.6 & 3.7 \\
\hline \multirow[t]{2}{*}{9.0} & $\mathrm{H}_{2} \mathrm{O}$ & $3.4 \times 10^{4}$ & 1.4 & 102 & b.d. & 4 & 2.9 & 2.9 \\
\hline & $\mathrm{D}_{2} \mathrm{O}$ & $3.4 \times 10^{4}$ & 2 & 95 & b.d. & 4 & 2.9 & 2.9 \\
\hline 9.5 & $\mathrm{H}_{2} \mathrm{O}$ & & & 95 & & 5 & & 2.0 \\
\hline
\end{tabular}

$k_{2}, k_{5}$, and $K_{\mathrm{d} \text {,obs }}$ values are the parameters determined from the analysis of the experimental traces at $455 \mathrm{~nm}$ and used for simulations; the $k_{1}, k_{-1}$, and $K_{\mathrm{d}, \text { theor }}$ values are the parameters obtained from simulation of the experimental traces using Specfit/32 (see Eq. (5a), Table 2 and text for details).

b.d.=below detection.

Fig. 5B displays the $\mathrm{pH}$ dependence of the term $k_{\mathrm{r}}$ (Eq. (6); the reciprocal of the slope of $1 / k_{\text {obs } 1}$ vs. $1 /[\mathrm{S}]$ from double reciprocal plots, according to Ref. [20]):

$$
k_{\mathrm{r}}=\frac{k_{1} \times k_{2}}{\left(k_{-1}+k_{2}\right)}
$$

The utility of $k_{\mathrm{r}}$, which is equivalent to $k_{2} / K_{\mathrm{d} \text {,app }}$, has been discussed elsewhere [10]. Thus, $k_{\mathrm{r}}$ reduces to $k_{1}$ when $k_{2} \gg k_{-1}$ and can approximate $k_{1} / 2$ when $k_{-1} \approx k_{2}$. Based on the estimations obtained from simulations (cf. above and Table 3 ), the lowest limit of $k_{1}$ approaches the value of $k_{2}$ at $\mathrm{pH}<8.0$. On the other hand, $k_{-1}$ is $\ll k_{2}$ at $\mathrm{pH}$ values $\geq 9.0$ and therefore only in this case does $k_{\mathrm{r}}$ reduce to $k_{1}$. In contrast, with wild-type $\mathrm{RgDAAO} k_{-1} \approx k_{2}$ at all pH values [10]. With S335G RgDAAO the $\mathrm{pH}$ dependence of $k_{\mathrm{r}}$ can be fit using the simpler Eq. (3a) and a single ionization (with an apparent $\mathrm{p} K_{\mathrm{a}} \approx 7.8$; see Fig. 5B). This is analogous to what is found for the mutant with $k_{\text {red }}$ and is in contrast to the behavior of $k_{\mathrm{r}}$ in the case of wild-type RgDAAO [10].

Apparent binding constants $K_{\mathrm{d}}$ can be obtained from the reciprocal of the abscissa intercept in the double-reciprocal plots of $k_{\text {obs1 }}$ Vs. [D-alanine]. However, based on similar arguments as presented above for $k_{\mathrm{r}}$, such a value corresponds to the true $K_{\mathrm{d}}$ $\left(=k_{-1} / k_{1}\right)$ only when $k_{-1} \gg k_{2}$ [14]. This situation does not apply to wild-type and S335G RgDAAO at pH values $\geq 7.5$ (see Table 3); thus, the corresponding estimated values are apparent ones. From the data shown in Table 3, it is apparent that there is a substantial increase in $K_{\text {dapp }}$ for S335G RgDAAO below pH 7.5 (this is similar to what was observed with wild-type RgDAAO [10]). The $\mathrm{p} K \sim 6.5$ that was estimated for wild-type RgDAAO [10] appears to be somewhat lower with the mutant; it cannot, however, be obtained with better precision due to the instability of the protein at low $\mathrm{pH}$.

Product dissociation from $\mathrm{E} \sim \mathrm{FAD}_{\text {red }} \sim \mathrm{P}$ into free keto acid and $\mathrm{NH}_{4}^{+}$corresponds to the second phase in the reductive halfreaction experiments, which is distinct from flavin reduction and which accounts for a small absorbance change at both 455 and $530 \mathrm{~nm}$ (see above). The rates of this phase $\left(k_{5}\right.$ in Eq. (5)) are slightly pH-dependent, the values ranging from $1.6(\mathrm{pH} 6.0)$ to $5 \mathrm{~s}^{-1}$ (pH 9.5).

Steady-state studies with the S335G RgDAAO mutant were conducted based on the method of Gibson [15] and were conceived to complement the measurements of the reductive half-reaction described above. The rates obtained for the S335G

Fig. 5. $\mathrm{pH}$ dependence of kinetic parameters for the anaerobic reduction of wild-type and S335G RgDAAOs with D-alanine. Data were obtained from stoppedflow experiments such as those depicted in Fig. 4. (A) Dependence of $k_{\text {red }}$, the rate constant of flavin reduction for wild-type RgDAAO (•, adapted from [10]), and for the S335G mutant ( $\mathbf{\square})$. The continuous line (curve 1) through the data points for wild-type RgDAAO is the fit for a finite value at high and low $\mathrm{pH}$ with an intermediate plateau using two $\mathrm{p} K_{\mathrm{a}}$ values $\left(=5.7\right.$, and 8.35 , Eq. (3b)). The dotted line (- - , curve (2)) is a curve generated using the same high $\mathrm{pH}\left(905 \mathrm{~s}^{-1}\right.$ ) and low $\mathrm{pH}\left(45 \mathrm{~s}^{-1}\right)$ values obtained from the fit to curve (1) and a single $\mathrm{p} K_{\mathrm{a}}(=8.35)$ based on Eq. (3a). The continuous line (curve (3)) through the data points for $\mathrm{S} 335 \mathrm{G}$ RgDAAO is the fit for a finite value at high and low $\mathrm{pH}$ using one $\mathrm{p} K_{\mathrm{a}}\left(=7.7\right.$, Eq. (3a)). For comparison, the $k_{\text {cat }}$ values determined for S335G under similar experimental conditions are reported (O). (B) Dependence of the term $k_{\mathrm{r}}\left(=k_{2} / K_{\mathrm{d} \text {,app }}\right.$, see text) for wild-type () and S335G (ם) RgDAAOs. Curve (1, -) is the fit obtained using Eq. (3b), as reported earlier for wild-type RgDAAO [10]. Curve (2) is the fit obtained using Eq. (3a) for the S335G mutant data, in which $k_{\mathrm{AH}}$ has either a finite value or is $=0$ ( - and - - -, respectively). Comparison of these two curves (2) demonstrates that for $k_{\mathrm{r}}$ a differentiation between the two variants ( $k_{\mathrm{r}}$ with or without low $\mathrm{pH}$ finite values) is not feasible. The inserts in A and B are the same representations as in the main plots; however, they are in logarithmic form to better show the data at low pH. (C) pH dependence of the ratio of the kinetic parameters $k_{\text {red }}(\boldsymbol{\square})$ and $k_{\mathrm{r}}(\boldsymbol{\bullet})$ determined for wild-type and S335G RgDAAOs. The symbols are the ratio of the experimental data points reported in A and B. Curve (1) is the ratio of fits (1) and (3) for $k_{\text {red }}$ of A. Curve (2) is the ratio of curves (1) and (2) for $k_{\text {red }}$ of A (see text for further explanations). Curve (3) is the ratio of fits (1) and (2) for $k_{\mathrm{r}}$ of $\mathrm{B}$ (truncated below pH 6). 
Table 4

Comparison of apparent ionization constants deduced from the $\mathrm{pL}$ dependence $(\mathrm{L}=\mathrm{H}$ or $\mathrm{D})$ of kinetic parameters for the reductive half-reaction of wild-type [10] and S335G RgDAAO with D-alanine as substrate

\begin{tabular}{|c|c|c|c|}
\hline \multirow[t]{2}{*}{$\mathrm{p} K$ derived from parameter } & \multicolumn{2}{|c|}{ Wild-type RgDAAO } & \multirow{2}{*}{$\frac{\mathrm{S} 335 \mathrm{G} \text { RDAAO }}{\mathrm{p} K_{\mathrm{a}}}$} \\
\hline & $\mathrm{p} K_{\mathrm{a} 1}$ & $\mathrm{p} K_{\mathrm{a} 2}$ & \\
\hline$k_{\text {red }}$ & $\begin{array}{l}5.7 \pm 0.3 \\
5.85 \pm 0.6\end{array}$ & $8.35 \pm 0.2$ & $7.7 \pm 0.1$ \\
\hline$K_{\text {d,app }}$ & $\begin{array}{l}6.45 \pm 0.3 \\
6.6 \pm 0.1\end{array}$ & & $5.2 \pm 0.2$ \\
\hline$k_{\mathrm{r}}\left(=k_{\mathrm{red}} / K_{\mathrm{d}, \mathrm{app}}\right)$ & $\begin{array}{l}7.0 \pm 0.1 \\
7.5 \pm 0.2\end{array}$ & $9.0 \pm 0.1$ & $7.8 \pm 0.2$ \\
\hline Solvent KIE, $k_{\text {red }}$ & $7.2 \pm 0.2$ & & $6.6 \pm 0.1$ \\
\hline
\end{tabular}

$k_{\text {red }}$ is the rate constant of the first phase of flavin reduction $k_{\mathrm{obs} 1}$ at infinite substrate concentration; $k_{\mathrm{r}}$ is the reciprocal of the slope of the double reciprocal plot of the rate of flavin reduction vs. the substrate concentration [20]. $K_{\mathrm{d} \text {,app }}$ and $\mathrm{p} K_{\mathrm{a}}$ values are apparent ones. The values in italics are those estimated for wildtype $\mathrm{RgDAAO}$ in $\mathrm{D}_{2} \mathrm{O}[10]$.

mutant are slower than those for wild-type RgDAAO and thus easier to evaluate. The $\mathrm{pH}$ dependence of the turnover numbers in the $\mathrm{pH}$ range $6.0-9.5$ is depicted in Fig. 5A. The correspondence of $k_{\text {cat }}$ with $k_{\text {red }}$, the rate constant of flavin reduction, demonstrates that this latter step is rate-limiting in this $\mathrm{pH}$ range. Table 4 lists the $\mathrm{p} K_{\mathrm{a}}$-deduced values for $\mathrm{S} 335 \mathrm{G}$ in comparison to those reported earlier for wild-type RgDAAO [10].

\subsection{Solvent KIEs and proton inventories in the reductive half-reaction}

The rationale for these studies is the hypothesis put forward earlier [10] that $\mathrm{S} 335-\mathrm{OH}$ is involved in deprotonation of the substrate $\alpha-\mathrm{NH}_{3}^{+}$. Specifically, such a role should be reflected in the $\mathrm{pH}$ dependence of the solvent KIE. A substantial effect is expected at $\mathrm{pH}<\mathrm{p} K_{\mathrm{a}}$ of the group $\left(\alpha-\mathrm{NH}_{3}^{+}\right.$vs. $\left.\alpha-\mathrm{ND}_{3}^{+}\right)$, while at $\mathrm{pH}>\mathrm{p} K_{\mathrm{a}}$ no effect should occur. Rate constants of the reductive half-reaction of wild-type $\mathrm{RgDAAO}$ are not affected by prolonged (pre)incubation in $\mathrm{D}_{2} \mathrm{O}$ buffer [10]; thus (slow) deuterium exchange processes on the protein do not interfere. The reductive half-reaction of $\mathrm{S} 335 \mathrm{G}$ was measured in $\mathrm{D}_{2} \mathrm{O}$ buffer at $\mathrm{pL}$ $(\mathrm{L}=\mathrm{H}$ or $\mathrm{D}) 6,7,8$, and 9 over a $0.1-210-\mathrm{mM}$ range of substrate concentrations. From the experimental traces substantial KIE on flavin reduction is evident at low pL, while at $\mathrm{pL} 9$ the $455 \mathrm{~nm}$ vs. time traces for experiments carried out in $\mathrm{H}_{2} \mathrm{O}$ and $\mathrm{D}_{2} \mathrm{O}$ are practically indistinguishable (Fig. 6). An evaluation of data from experiments in $\mathrm{H}_{2} \mathrm{O}$ at all pH values and in $\mathrm{D}_{2} \mathrm{O}$ at $\mathrm{pH}$ 7-9 can be achieved using bi-exponential fit routines. This fitting procedure, however, is not feasible with the pD 6 data because of the similarity of the rates for steps $k_{2}, k_{-2}$, and $k_{5}$. In this case the rate constants were estimated by simulating the experimental traces with Specfit/32 software, which is based on time-resolved spectral deconvolution [10]. For this simulation, known absorbance spectra of $E \sim F A D_{\text {ox }}, E \sim F A D_{\text {red }} \sim P$, and $E \sim F A D_{\text {red }}$ enzyme forms were introduced as fixed parameters into the program and yielded a satisfactory correspondence with the experimental trace (Fig. 6). Similar data simulations were performed on selected sets of experimental data at all $\mathrm{pH}$ values, in $\mathrm{H}_{2} \mathrm{O}$ and $\mathrm{D}_{2} \mathrm{O}$ : the rate constants estimated by this method are reported in Table 3. The results of this analysis are compatible with the solvent H/D substitution affecting only the rates of flavin reduction $k_{2}$, all other kinetic parameters remaining practically unaltered.

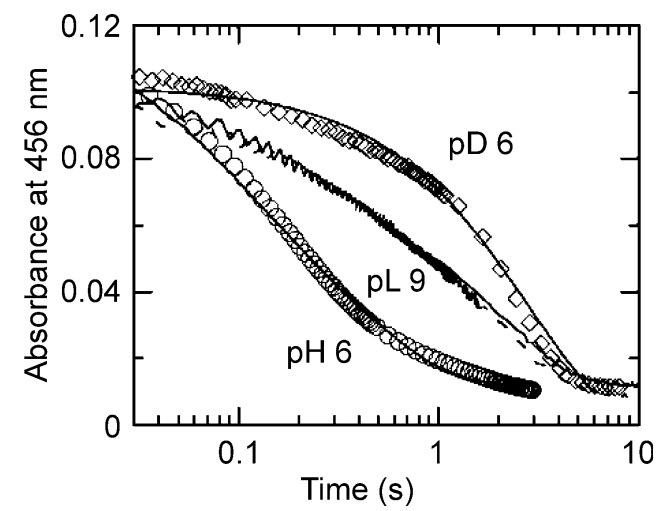

Fig. 6. Comparison of time courses of the anaerobic reduction of S335G RgDAAO with D-alanine at pL (=L or D) 6.0 and 9.0. Anaerobic solutions of enzyme $(10 \mu \mathrm{M})$ and $21 \mathrm{mM}$ D-alanine at $\mathrm{pL} 6\left(\mathrm{O}\right.$ in $\mathrm{H}_{2} \mathrm{O}, \diamond$ in $\left.\mathrm{D}_{2} \mathrm{O}\right)$ or $0.1 \mathrm{mM}$ D-alanine at pL 9 were mixed in the stopped-flow instrument, at $25{ }^{\circ} \mathrm{C}$, as detailed in Fig. 4. The continuous lines through the $\mathrm{pL}=6$ data points are simulations (Specfit/32; see Materials and methods section for details), based on the sequence of steps shown in Eq. (5a) and the known extinction coefficients of the oxidized and reduced enzyme forms (see text). 


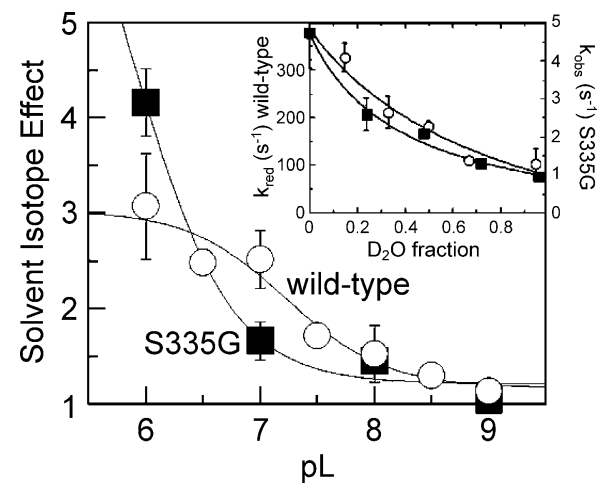

Fig. 7. Dependence of the solvent KIE for $k_{\text {red }}$ on $\mathrm{pL}(\mathrm{L}=\mathrm{H}, \mathrm{D})$. The data points are derived from experiments such as those depicted in Figs. 4 and 6 , and from values reported in Table 3. The data are the ratios of the rates of flavin reduction $k_{\text {red }}$ (for saturating [D-alanine]) in $\mathrm{H}_{2} \mathrm{O}$ to those in $\mathrm{D}_{2} \mathrm{O}$. The continuous line through the wild-type data points $(\mathrm{O})$ is the fit obtained using Eq. (3a) (apparent $\mathrm{p} K=7.2$ ). That through the $\mathrm{S} 335 \mathrm{G}$ data points $(\boldsymbol{\square})$ was generated using an arbitrary (fixed) upper limit $=5$ for the solvent KIE at low pH (apparent $\mathrm{p} K=6.6$ ). Inset: Proton inventory for the parameter $k_{\text {red }}$ for S335G ( $\left.\mathbf{\square}\right)$ and comparison with wild-type RgDAAOs [10] at pL 6. The experimental data were fit using Eq. (4).

The combination of the dependence of $k_{\text {red }}$ on $\mathrm{pL}$ with that on the solvent $\left(\mathrm{H}_{2} \mathrm{O}\right.$ or $\left.\mathrm{D}_{2} \mathrm{O}\right)$ yields the $\mathrm{pL}$ dependence of the solvent KIE that is depicted in Fig. 7. For data fitting, and based on the results of Fig. 6, the KIE was fixed $=1$ at $\mathrm{pH} \geq 9$. For the S335G data reported in Fig. 7, the line through the data points is simply an approximation obtained on the assumption that the KIE approaches a finite value (about 5) at $\mathrm{pH}<6$.

Proton inventories were investigated to assess the number and the location of the exchangeable protons contributing to the observed solvent KIE. At $\mathrm{pL}=6$, where the solvent $\mathrm{KIE}$ is large and with the $\mathrm{S} 335 \mathrm{G}$ mutant, the proton inventory is not linear (Fig. 7 inset): it is consistent with an isotope effect generated by two exchangeable sites in the transition state [10]. The overall behavior of the mutant is thus similar to that observed for wild-type RgDAAO and mammalian DAAO [21].

\section{Discussion}

The spectral properties, the extent of flavin radical stabilization, and the $\mathrm{p} K_{\mathrm{a}}$ for the flavin $\mathrm{N}(3)-\mathrm{H}$ dissociation of the $\mathrm{S} 335 \mathrm{G}$ mutant, which are taken to reflect the microscopic electrostatic environment at the active site, are very similar to those of wild-type RgDAAO. Binding constants $\left(K_{\mathrm{d}}\right)$ for most ligands and in particular that for sulfite, which correlate with the redox potential of the flavin [18], are within one order of magnitude compared to those of wild-type $\operatorname{RgDAAO} . V_{\max \text {,app }}$ for D-alanine with the S335G mutant is lower than that for wild-type RgDAAO and the apparent catalytic efficiency $V_{\max } / K_{\mathrm{m}}$ for Daspartate is essentially unaltered (Table 1). Taken together, these data suggest that the S335G mutation has only minor effects on the microenvironment at the active site of RgDAAO and it does not affect substrate specificity.

A significant difference with the wild-type DAAO is the lack of any reactivity towards D-lactate following the substitution of S335 (Fig. 2), pointing to an alteration of orbital orientation required for catalysis between the bound D-lactate and the $\mathrm{N}(5)$ flavin position. In a more general context, it should be noted that a significant increase in the activity of RgDAAO towards acidic D-amino acids was observed when an additional positive charge was introduced into the active site with the introduction of an arginine residue at position 213 that also flanks the cavity surrounding the substrate side chain [22]. The absence of any reactivity toward D-lactate for the $\mathrm{S} 335 \mathrm{G}$ mutant suggests that the $\mathrm{S} 335-\mathrm{OH}$ contributes an important element to the dehydrogenation reaction, at least in the case of this "slow" substrate, possibly a function in the removal of the substrate $\alpha-\mathrm{OH}$ hydrogen by its side chain as depicted in Scheme 1 .

The finding that the S335G mutant studied is catalytically competent excludes an essential role of $\mathrm{S} 335-\mathrm{OH}$ in catalysis. On the other hand, both $k_{\text {cat }}$ and $k_{\text {red }}$ (the rate of enzyme reduction) are lower for $\mathrm{S} 335 \mathrm{G}$ than for wild-type RgDAAO, in particular in the region $\mathrm{pH}$ 6-7 (Tables 2 and 3 , and Fig. 5A). This indicates that this group is a component of the active site machinery responsible for the enzyme catalytic efficiency, probably in optimizing critical steps. One such factor might be the fixation/orientation of the reaction partners such that alignment of the interacting orbital is maximized $[1,23]$. A second function, as already
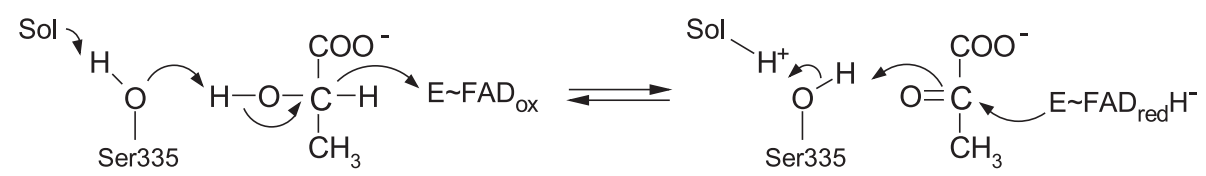

Scheme 1. Possible role of S335-OH in the dehydrogenation of D-lactate by RgDAAO. FAD (oxidized or reduced forms) denotes the flavin cofactor at the active center. 
suggested for the role in the dehydrogenation of D-lactate (Scheme 1), would consist in the assistance in transfer of $\mathrm{H}^{+}$ originating from the substrate $\alpha \mathrm{NH}_{3}^{+}$to solvent during catalysis. This is depicted in Scheme 3 (see below) and infers that the role should be evident below the $\mathrm{p} K$ of the $\alpha$ amino group of the bound substrate. RgDAAO thus works by (at least) the two different, pH-dependent mechanisms ((a) and (b)) that are depicted in Scheme 2. The difference between these variants is that in (a), concomitantly with dehydrogenation, a $\mathrm{H}^{+}$must be removed from the amino group and transferred to bound solvent this occurring concertedly [10]. This is necessary since at the active center there is no base that could function in stabilizing this $\mathrm{H}^{+}$.

The second main difference between the wild-type and S335G RgDAAOs is the different $\mathrm{pH}$ dependence of both $k_{\text {red }}$ and $k_{\mathrm{r}}$ kinetic parameters. In a previous study [10], the $\mathrm{pH}$ dependence of these kinetic parameters for wild-type RgDAAO (Fig. 5) was interpreted as having a plateau of finite activity at low $\mathrm{pH}$ : this would be consistent with a dehydrogenation mechanism for which an active site base is not mandatory. The evidence for such a plateau is much clearer with the $\mathrm{S} 335 \mathrm{G}$ mutant for both the terms $k_{\text {red }}$ and $k_{\text {cat }}$ (Fig. 5A), further supporting the original deduction [1]. The coincidence of the values of $k_{\text {red }}$ with $k_{\text {cat }}$ for the $\mathrm{S} 335 \mathrm{G}$ mutant at all $\mathrm{pH}$ values (Fig. $5 \mathrm{~A}$ ) also demonstrates that $k_{\text {red }}$ (equivalent to $k_{2}$, see Eq. (5)) is rate-limiting over the whole range. Further, in Ref. [10] we deduced that the observed $\mathrm{p} K \approx 8$ found with wild-type RgDAAO (curve 1 , Fig. 5A) reflects an ionization in the $\mathrm{E} \sim \mathrm{FAD}_{\mathrm{ox}} \sim \mathrm{S}$ complex and specifically that of the substrate $\alpha$-amino group [10,24]: the alanine $\mathrm{p} K_{\mathrm{a}}=9.7$ would therefore be significantly lowered upon binding. The $k_{\text {red }}$ and $k_{\text {cat }} \mathrm{pH}$ profiles for the S335G mutant (Fig. 5A) are much simpler in their shape, reflecting a single apparent $\mathrm{p} K_{\mathrm{a}}$ that would be somewhat lowered (Table 4). This fully supports the aforementioned $\mathrm{p} K$ attribution. Removal of the $\mathrm{S} 335-\mathrm{OH}$ function suppresses a "saddle" observed in the profiles of wild-type enzyme that corresponds to an apparent ionization with a $\mathrm{p} K \approx 6$. The present data do not allow an attribution of this apparent $\mathrm{p} K$ to a specific microscopic phenomenon or to a combination of kinetic steps. Comparison of the theoretical curve (2) (generated using the low- and high-pH extremes

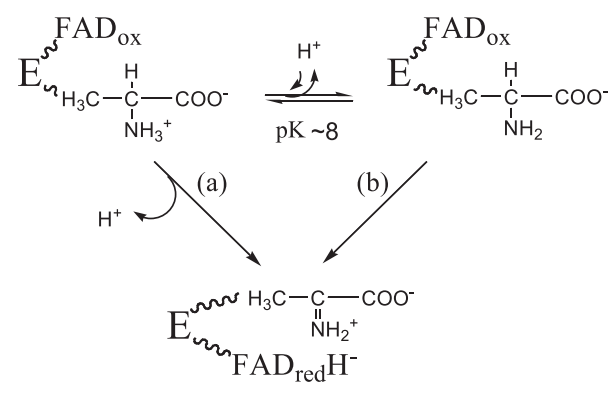

Scheme 2. $\mathrm{pH}$ dependence of the mechanism of dehydrogenation of substrate by RgDAAO. Enzyme-bound substrate can exist in its $\alpha$-amino protonated and unprotonated forms that are linked by a $\mathrm{p} K_{\mathrm{a}} \approx 8$.

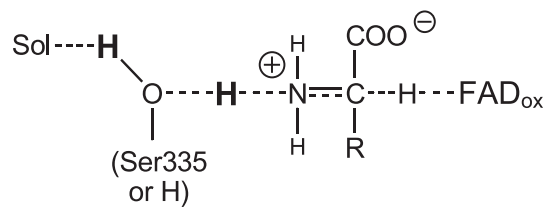

Scheme 3. Possible transition state occurring during the DAAO mediated dehydrogenation of an amino acid substrate in its $\alpha \mathrm{NH}_{3}^{+}$form. With RgDAAO the $-\mathrm{OH}$ group mediating transfer of $\mathrm{H}^{+}$to the solvent is "covalently linked" to the protein moiety, while with mammalian DAAO it would consist in a probably fixed $\mathrm{H}_{2} \mathrm{O}$ molecule occupying the same position.

and the $\mathrm{p} K \approx 8$ of curve (1)) to the fit of the $\mathrm{S} 335 \mathrm{G}$ RgDAAO data points, curve (3) in Fig. $5 \mathrm{~A}$, shows that the two curves have the same $\mathrm{p} K \approx 8$ and similar shapes but that the absolute values of $k_{\text {red }}$ differ. If this analogy was taken to reflect similar basic mechanisms, then the difference between curves (1) and (2) in Fig. 5A would thus be related to the effects of the $\mathrm{S} 335-\mathrm{OH}$ group. This difference is better displayed graphically in Fig. 5C: the inflections at $\mathrm{pHs} \approx 6.5, \approx 8$, and $\approx 9$ in curve (1) originate from the division of the curves (1) and (3) in Fig. 5A that have 2 vs. 1 apparent $\mathrm{p} K \mathrm{~s}$, respectively. The ratio $k_{\mathrm{r}}$ (wild-type)/ $k_{\mathrm{r}}(\mathrm{S} 335 \mathrm{G}$ ) (curve (3) in Fig. $3 \mathrm{C}$ ) is $\approx 2$ at $\mathrm{pH}>8.5$, which is in agreement with the deduction that at high $\mathrm{pH} k_{\mathrm{r}} \approx k_{1}$ (due to $k_{2} \gg k_{1}$; see Eq. (6) and Table 3) [20]. This is consistent with $k_{1}$ being a $\mathrm{H}^{+}$-independent step, the rate of which is only slightly altered by the S335 mutation (see Table 2 at $\mathrm{pH} 8.5$ ). Below the apparent $\mathrm{p} K \approx 8$, the importance of S335-OH for $k_{\mathrm{r}}$ appears to increase substantially (Fig. 5C, line 3): this value approaches the ratio $k_{\text {red }}$ (wild-type) $/ k_{\text {red }}(\mathrm{S} 335 \mathrm{G}$ ) (compare lines (1) and (3) in Fig. 5C), indicating that at low $\mathrm{pH}$ the effect of the mutation consists in a decrease in $k_{2}$ (see above). Furthermore, there is also a significant effect of $\mathrm{pH}$ on $k_{-1}$ the rate of substrate dissociation for the mutant S335G: this rate constant being significantly slower when the substrate is in the R$\mathrm{CH}\left(\mathrm{NH}_{2}\right)-\mathrm{COO}^{-}$form (Table 3).

It should be noted that the increase in the " $\mathrm{S} 335-\mathrm{OH}$ effect" on decreasing the $\mathrm{pH}$ from 8 to 6 corresponds to the increase in the solvent KIE (Fig. 7), which is assumed to originate in the rupture of (one of) the exchangeable substrate $\alpha \mathrm{N}-\mathrm{H}_{3}^{+}$bond(s). At $\mathrm{pL}=6$ the proton inventories (Fig. 7, inset) are consistent with an isotope effect generated by two exchangeable sites for S335G and wild-type RgDAAOs. A similarly bowl-shaped solvent inventory profile was reported for mammalian DAAO at $\mathrm{pH} 6$ [21]. A transition state in which two $\mathrm{H}^{+}$are in flight can be envisaged as depicted in Scheme 3.

Thus, a prima facie deduction is consistent with the S335-OH group being involved in the transfer of the $\mathrm{H}^{+}$ originating from the substrate $\alpha \mathrm{NH}_{3}^{+}$to bulk solvent [10]. With respect to the factors that might give rise to the "saddle", an ionization with a $\mathrm{p} K \approx 6$ can hardly be attributed to the $\mathrm{S} 335-\mathrm{OH}$ group since this would require a shift of $\approx 10$ units of its $\mathrm{p} K$, an unrealistic assumption. 
The finding of identical rates for $k_{\text {red }}$ at high $\mathrm{pH}$ in $\mathrm{H}_{2} \mathrm{O}$ and $\mathrm{D}_{2} \mathrm{O}$ (Figs. 6 and 7) is consistent with a mechanism such as (a) in Scheme 2, where the unprotonated form of the substrate $\alpha$-amino group is the reacting species, and in which no exchangeable $\mathrm{H}$-bond undergoes fission. With decreasing $\mathrm{pH}$ there is a transition $\alpha \mathrm{NH}_{2}=>\alpha \mathrm{NH}_{3}^{+}$that leads to a shift from mechanisms (b) to (a) in Scheme 2 and to an increase of the rate of substrate dissociation from the E$\mathrm{FAD}_{\text {ox }} \sim \mathrm{S}$ Michaelis complex. Accordingly, this is reflected by the appearance of a substantial solvent KIE with an apparent $\mathrm{p} K$ in the region 7-8 (Fig. 7).

In the 3D-structure of RgDAAO in complex with $\mathrm{D}$ alanine, the $\alpha \mathrm{NH}_{3}^{+}$group of the substrate is at $\approx 10 \AA$ from "bulk" solvent, i.e., it is not in contact with it, and there is no obvious, open channel that might serve in transfer (Fig. 1) [1]. $\mathrm{S} 335-\mathrm{OH}$ is not in contact with the $\alpha \mathrm{NH}_{3}^{+}$group of the substrate in the crystal structure [1]. However, by molecular modeling it can be shown that upon simple rotation around the $\alpha \mathrm{C}-\beta \mathrm{C}$ bond a position is obtained that allows $\mathrm{H}$-bond formation with the $\alpha \mathrm{NH}_{3}^{+}$. Based on the solvent inventory data (Fig. 7) that require two protons to be in flight in the transition state, we thus suggest that this could be the conformation required during catalysis at $\mathrm{pH}<\mathrm{p} K \approx 8$, where the substrate is in the $\alpha \mathrm{NH}_{3}^{+}$form. Alternatively, but less likely due to steric constraints (see Fig. 1), S335-OH could fix a water molecule that interacts with $\alpha \mathrm{NH}_{3}^{+}$. In both cases, the result would be a facilitated deprotonation of the substrate $\mathrm{\alpha NH}_{3}^{+}$form (Scheme 2). In other words, S335-OH is not essential for RgDAAO dehydrogenation catalysis: its role is an ancillary one leading to an optimization of catalysis under the specific conditions of RgDAAO.

Comparison of the active sites of related enzymes shows that G313 in mammalian DAAO [2] and Gly464 in LAAO [25] are present at the locus of $\mathrm{S} 335-\mathrm{CH}_{2}-\mathrm{OH}$ in RgDAAO (Fig. 1), the volume taken up by the $\mathrm{S} 335-\mathrm{CH}_{2}-\mathrm{OH}$ in RgDAAO most probably being occupied by solvent $\mathrm{H}_{2} \mathrm{O}$. At this point it might be conjectured on the molecular reasons for the presence of a serine $\mathrm{CH}_{2}-\mathrm{OH}$ side chain in RgDAAO that correlates with a higher rate of substrate dehydrogenation and catalytic activity compared to the mammalian counterpart. It should be kept in mind that catalysis in yeast and mammalian DAAOs have different rate-limiting steps [8,9]. This is the reductive (Eq. (1a)) and the oxidative half reaction (Eq. (1c)) with Rg- and pkDAAO, respectively. An increase in the rate of the reductive half-reaction would thus not be of any benefit for mammalian DAAO, while it might constitute an important advantage with $\mathrm{RgDAAO}$, in particular at acidic $\mathrm{pH}$ values where yeast cells grow efficiently. A further difference between the two types of enzyme consist in the presence of a "lid" at the active center that is assumed to control product dissociation in mammalian DAAO $[2,3]$. The presence of this "lid" might not be compatible with the steric requirements of a serine $\mathrm{CH}_{2}-\mathrm{OH}$ side chain that also is placed in the channel leading to the cofactor (Fig. 1). A further constant emerging from this comparison is the role of the backbone carbonyl groups of G464 in L-amino acid oxidase, G313 in pkDAAO and S335 in RgDAAO: they are all involved in binding of the amino group of the substrate/ ligand, thus probably contributing in its fixation during the hydride transfer process.

\section{Acknowledgements}

This work was supported by grants from Italian MIUR to Dr. M.S. Pilone (PRIN 2002 Prot. 2002057751), from FAR 2001 to L. Pollegioni and FAR 2002 and 2003 to M.S. Pilone.

\section{References}

[1] S. Umhau, L. Pollegioni, G. Molla, K. Diederichs, W. Welte, M.S. Pilone, S. Ghisla, The X-ray structure of D-amino acid oxidase at very high resolution identifies the chemical mechanism of flavin-dependent substrate dehydrogenation, Proc. Natl. Acad. Sci. U. S. A. 97 (2000) 12463-12468.

[2] A. Mattevi, M.A. Vanoni, F. Todone, M. Rizzi, A. Teplyakov, A. Coda, M. Bolognesi, B. Curti, Crystal structure of D-amino acid oxidase: a case of active site mirror-image convergent evolution with flavocytochrome $b_{2}$, Proc. Natl. Acad. Sci. U. S. A. 93 (1996) 7496-7501

[3] H. Mizutani, I. Miyahara, K. Hirotsu, Y. Nishina, K. Shiga, C. Setoyama, R. Miura, Three-dimensional structure of porcine kidney D-amino acid oxidase at $3.0 \AA$ resolution, J. Biochem. (Tokyo) 120 (1996) 14-17.

[4] C.M. Harris, G. Molla, M.S. Pilone, L. Pollegioni, Studies on the reaction mechanism of Rhodotorula gracilis D-amino acid oxidase: role of the highly conserved Tyr223 on substrate binding and catalysis, J. Biol. Chem. 274 (1999) 36235-36240.

[5] G. Molla, D. Porrini, V. Job, L. Motteran, C. Vegezzi, S. Campaner, M.S. Pilone, L. Pollegioni, Role of arginine 285 in the active site of Rhodotorula gracilis D-amino acid oxidase, J. Biol. Chem. 275 (2000) 24715-24721.

[6] A. Boselli, S. Sacchi, V. Job, M.S. Pilone, L. Pollegioni, Role of tyrosine 238 in the active site of Rhodotorula gracilis D-amino acid oxidase. A site directed mutagenesis study, Eur. J. Biochem. 269 (2002) $1-10$.

[7] L. Pollegioni, K. Diederichs, G. Molla, S. Umhau, W. Welte, S. Ghisla, M.S. Pilone, Yeast D-amino acid oxidase basis of its catalytic properties, J. Mol. Biol. 324 (2002) 535-546.

[8] L. Pollegioni, B. Langkau, W. Tischer, S. Ghisla, M.S. Pilone, Kinetic mechanism of D-amino acid oxidase from Rhodotorula gracilis and Trigonopsis variabilis, J. Biol. Chem. 268 (1993) 13850-13857.

[9] D.J. Porter, J.G. Voet, H.J. Bright, Mechanistic features of the Damino acid oxidase reaction studied by double stopped flow spectrophotometry, J. Biol. Chem. 252 (1977) 4464-4473.

[10] C.M. Harris, L. Pollegioni, S. Ghisla, $\mathrm{pH}$ and kinetic isotope effects in D-amino acid oxidase catalysis, Eur. J. Biochem. 268 (2001) 1-18.

[11] J. Sambrook, E.P. Fritsch, T. Maniatis, Molecular Cloning: A Laboratory Manual, 2nd ed., Cold Spring Harbor Laboratory Press, Cold Spring Harbor, NY, 1989.

[12] G. Molla, C. Vegezzi, M.S. Pilone, L. Pollegioni, Overexpression in Escherichia coli of a recombinant chimeric Rhodotorula gracilis D-amino acid oxidase, Prot. Express. Purif. 14 (1998) 289-294.

[13] V. Massey, P. Hemmerich, Photoreduction of flavoproteins and other biological compounds catalyzed by deazaflavins, Biochemistry 17 (1978) 9-16. 
[14] S. Strickland, G. Palmer, V. Massey, Determination of dissociation constants and specific rate constants of enzyme-substrate (or proteinligand) interactions from rapid reaction kinetic data, J. Biol. Chem. 250 (1975) 4048-4052.

[15] Q.H. Gibson, B.E.P. Swoboda, V. Massey, Kinetics and mechanism of action of glucose oxidase, J. Biol. Chem. 259 (1964) 3927-3934.

[16] W.W. Cleland, Determining the chemical mechanisms of enzymecatalyzed reactions by kinetic studies, Adv. Enzymol. Relat. Areas Mol. Biol. 45 (1982) 273-387.

[17] R. Lumry, E.L. Smith, R.R. Glatz, Kinetics of carboxypeptidase action. Effect of various extrinsic factors on kinetic parameters, J. Am. Chem. Soc. 73 (1951) 4330-4340.

[18] V. Massey, F. Muller, R. Feldberg, M. Schuman Jorns, P.A. Sullivan, L.G. Howell, S.G. Mayhew, R.G. Matthews, G.P. Foust, The reactivity of flavoproteins with sulfite. Possible relevance to the problem of oxygen reactivity, J. Biol. Chem. 244 (1969) 3999-4006.

[19] K. Dalziel, The interpretation of kinetic data for enzyme-catalysed reactions involving three substrates, Biochem. J. 114 (1969) 547-556.
[20] D.J.T. Porter, H.J. Bright, Interpretation of the $\mathrm{pH}$ dependence of flavin reduction in L-amino acid oxidase reaction, J. Biol. Chem. 255 (1980) 2969-2975.

[21] J.M. Denu, P.F. Fitzpatrick, $\mathrm{pH}$ and kinetic isotope effects on the oxidative half-reaction of D-amino-acid oxidase, J. Biol. Chem. 269 (1994) 15054-15059.

[22] S. Sacchi, S. Lorenzi, G. Molla, M.S. Pilone, C. Rossetti, L. Pollegioni, Engineering the substrate specificity of D-amino acid oxidase, J. Biol. Chem. 277 (2002) 27510-27516.

[23] A.D. Mesecar, B.L. Stoddard, D.E. Koshland Jr., Orbital steering in the catalytic power of enzymes: small structural changes with large catalytic consequences, Science 277 (1997) 202-206.

[24] S. Fersht, Measurement and magnitude of individual rate constants, Enzyme Structure and Mechanism, 1999, pp. 132-163.

[25] P.D. Pawelek, J. Chean, R. Coulombe, P. Macheroux, S. Ghisla, A. Vrielink, The structure of L-amino acid oxidase reveals the substrate trajectory into an enantiomerically conserved active site, EMBO J. 19 (2000) 4204-4215. 